\title{
El dolor de los subalternos y el deseo de una revolución inconclusa: Narrativas sobre la violencia politica en la Nación Aymara - Perú
}

\section{The pain of the subalterns and the desire for an unfinished revolution: Narratives about political violence in the Aymara Nation - Peru}

\author{
Jesús Wiliam Huanca-Arohuanca ${ }^{1, a}$ \\ https://orcid.org/0000-0002-7353-1166
}

Franklin Américo Canaza-Choque 2, b
https://orcid.org/0000-0002-1929-6054

Emilio Flores Mamani ${ }^{3, c}$

https://orcid.org/0000-0002-0317-6867

\author{
${ }^{1}$ Universidad Nacional de San Agustín de Arequipa, Arequipa, Perú. \\ ${ }^{2}$ Universidad Católica de Santa María, Arequipa, Perú. \\ ${ }^{3}$ Universidad Nacional del Altiplano, Puno, Perú.
}

Recibido: 24/07/2020

Aceptado: 01/11/2020

\section{Resumen}

En las líneas que vienen, como macro objetivo, se intentará examinar la violencia política y las pretensiones de revolución por los actores de la Nación Aymara(NAM), al encontrarse con un profundo impacto causado por los grupos sediciosos y el Estado peruano en el contexto de la década oscura de los años '80 y '90 del siglo pasado que, todavía queda como secuela en la memoria colectiva de las víctimas. Considerando el enfoque cualitativo, la entrevista en profundidad y el análisis de discurso como orientación hermenéutica fundamental, se examinan las percepciones de los 12 actores que en el entramado de la violencia fueron dirigentes. Los resultados evidencian que, la violación de los Derechos Humanos (DH) bajo la represión, persecución y las desapariciones selectivas en detrimento de la población Aymara, ha generado tensiones, miedo, paranoia y el deseo de revolución contra los grupos insurgentes y el mismo Estado que en su momento fue cómplice del genocidio hacia el corazón de los habitantes de la NAM. En conclusión, solo la apertura de los canales democráticos vinculantes entre el gobierno y los aymaras, podrá redefinir nuevos espacios de diálogos transdisciplinares custodiados por la verdad y la justicia imperativa.

Palabras clave: Violencia política, memoria colectiva, revolución, conflicto armado, violación de los derechos humanos.

\begin{abstract}
In the lines that come, as a target macro, attempts will be made to examine the political violence and claims of revolution by the actors of the Aymara Nation (NAM) as it encounters a profound impact caused by the seditious groups and the Peruvian state in the context of the dark decade of the 80 s and 90 s of the last century that remains a sequel to the collective memory of the victims. Considering the qualitative approach, in-depth interview and discourse analysis as a fundamental hermeneutic orientation, the perceptions of the 12 actors who were leaders in the fabric of violence are examined. The results show that the violation of Human Rights (HR) under repression, persecution and selective disappearances to the detriment of the Aymara population, creates tensions, fear, paranoia and the desire of revolution against insurgent groups and the same State that was once complicit in the genocide to the heart of the inhabitants of the NAM. In conclusion, only the opening of binding democratic channels between government and Aymara can redefine new spaces for transdisciplinary dialogues guarded by truth and imperative justice.
\end{abstract}

Keywords: Political violence, collective memory, revolution, armed conflict, violation of human rights. 


\section{Introducción}

Cuando a principios del milenio se consolidaba la admisión de los países del ex-bloque soviético a la comunidad democrática internacional, el panorama mundial ofrecía motivos para considerar que las dos instituciones fundamentales del desarrollo político de la segunda posguerra, la democracia y los $\mathrm{DH}$, habían llegado para quedarse (Valdés, 2020). Desde esa perspectiva, el autor nominado sustenta que, Fukuyama (1989) da una lectura errada de ese texto célebre que dio pie a una dilatada controversia acerca del fin de la historia que, según el equívoco, habría ocasionado el triunfo de la democracia liberal sobre las distintas formas de autocracia. Porque, ese excesivo optimismo liberal, que poco fue menoscabado por sus detractores, fue empañado por Huntington (1993) cuando advirtió que la nueva división que enfrentaba la humanidad era un choque de civilizaciones. A pesar todo ello, el equívoco consistió en que el atractivo hegeliano de la etiqueta fin de la historia por el triunfo del liberalismo pesó más que su propio argumento, cuando sustentó: "quizás el mismo prospecto de siglos de aburrimiento al final de la historia servirá para echar a andar la historia de nuevo" (Fukuyama, 1989, p. 18). Indudablemente, su juicio sobre el fin del socialismo soviético y maoísta fue la causa de fondo del rechazo a su tesis (Valdés, 2020).

Como se analiza en el apartado anterior, la tesis evidentemente mostró su error cuando en el mundo y en Perú el socialismo había quedado como óxido en el fondo de aquel país que no se sacudía aun de un fenómeno patológico llamado Partido Comunista del Perú-Sendero Luminoso (PCP-SL) y un Estado autoritario muy similar al anterior. A partir de ahí se habla de la violencia política que pulverizó la democracia por los que habían muerto millones y los DH al parecer en la NAM no tenían ni tienen cabida. Como se sabe, el Perú ha vivido el episodio de violencia más intenso, extenso y prolongado de toda su historia republicana. No obstante, a pesar de la importancia que adquirió el conflicto armado interno a lo largo de la década de 1980 y de la crisis generalizada en que se sumió el país, el PCP-SL fue y en cierta medida continúa siendo, singular con respecto a otros grupos armados de América Latina (AL). No solo porque fue la única guerrilla maoísta en todo el continente, sino por su carácter excepcionalmente letal (Degregori, 2011).
En efecto, el PCP-SL fue responsable por lo menos del $46 \%$ de víctimas mortales del conflicto armado interno, además, hay que tener en cuenta que en ningún país de AL, el porcentaje de víctimas fatales producidas por organizaciones subversivas llegó a los dos dígitos (Degregori, 2011). Por ello, cabe mencionar que el número total de muertos $\mathrm{y}$ desaparecidos causados por el conflicto armado interno peruano se puede estimar en 69,280 personas, dentro de un intervalo de confianza al 95\% cuyos límites superior e inferior son 61,007 y 77,552, respectivamente. Sin embargo, las proporciones relativas de las víctimas según los principales actores del conflicto serían: 46\% provocadas por el PCP-SL; 30\% provocadas por Agentes del Estado (AAE); y 24\% provocadas por otros agentes o circunstancias como: rondas campesinas, comités de autodefensa, Movimiento Revolucionario Túpac Amaru (MRTA), grupos paramilitares, agentes no identificados o víctimas ocurridas en enfrentamientos o situaciones de combate armado (Comisión de la Verdad y Reconciliación [CVR], 2003a; Degregori, 2011).

Con relación a la sierra sur del Perú, las incursiones de SL estuvieron presentes en toda la región altiplánica. Los principales ataques estuvieron dirigidos a las empresas asociativas, incrementándose de 15, en 1983, a 22 en 1984 y a 33 en 1985. En 1986 los senderistas efectuaron 83 ataques y el número de víctimas ascendió a 32. En 1987, las acciones de violencia se redujeron después que la columna senderista fuera diezmada, registrándose 35 ataques, sin embargo, se incrementaron a 77 en 1988 y a 97 en 1989 (CVR, 2003b). Si bien la violencia política concluye con la caída de las cúpulas de los movimientos subversivos y el retorno a la democracia conjuntamente con los DH. En apariencia la conducta de los actores sociales no se había modificado sustancialmente, y el Estado tampoco había recuperado su rol tuitivo (Canessa, 2011) como elemento regulador y pacificador de la nación.

Poniendo a flote los argumentos anteriores, en la NAM no se materializaron registros oficiales de las persecuciones y torturas, pero si, existen en la facticidad misma de la memoria colectiva de los actores. Entonces, la tarea está en mostrar el temor y el dolor de las víctimas a través de las narrativas recogidas desde el corazón de los pueblos aymaras con cierto afán hacia la revolución. Puesto que, el Perú y la región 
altiplánica ha experimentado durante los últimos treinta años una serie de experiencias traumáticas que exacerbaron sus problemas seculares y cuyas consecuencias siguen acosando la imaginación y las conductas individuales y colectivas. De ahí que, la violencia política como fenómeno social tiene grandes repercusiones sobre la salud mental de las poblaciones afectadas, tanto a nivel individual como colectivo y su abordaje debe ser multidimensional para dar respuesta a la complejidad de sus consecuencias (Cotler, 1997; Cueva, 2005; Vera-Márquez et al., 2015).

Frente a los argumentos presentados hasta ahí y teniendo claro el objetivo de investigación, el estudio intentará examinar la violencia política y las pretensiones de revolución por los actores de la NAM al encontrarse con cargas impactantes causados por los grupos insurrectos y el Estado peruano al mando de Fujimori-Montesinos en el contexto de la década sombría a finales del siglo $\mathrm{XX}$ que todavía queda como secuela en la memoria colectiva de las víctimas inocentes.

\section{Revisión de literatura}

\section{Violencia política}

Observando la realidad social y política que se vive actualmente en el mundo, se puede apreciar que, como en el pasado, la violencia política continúa siendo un medio para dominar a otros y establecer, cambiar o preservar un determinado orden social. Esa constante relación entre poder y violencia hace que la violencia política sea un tema complejo con consecuencias sociales, políticas y psicológicas, entre otras, de vital importancia para los seres humanos. Visto de esa manera, la necesidad y posibilidad de estudiar este fenómeno desde diferentes perspectivas teóricas resulta interesante para los investigadores de las ciencias sociales y humanas (Lúnecken, 2000; Barreto \& Borja, 2007).

En suma, la violencia política es considerada como el empleo de la fuerza para conquistar o para ejercer el poder. La violencia como elemento humano, social y político presente en la historia, representa en circunstancias múltiples y disímbolas, la conformación de la organización política que va sometiendo a la violencia en instituciones que debaten, ejecutan e imparten justicia, ejerciendo el poder como sujeto a derecho (Talancón, 2018). En el contexto del terrorismo interno, como lógica de acción, no es, no se denomina como violencia política, aunque en general sea una de sus prolongaciones (Wieviorka, 1992) desastrosas que el Perú y la NAM pudieron presenciar. Sino que, puede ser promocionada en el exterior como un modelo emular, pero, buena parte del mito se fundamenta en la idea de que estuvo exenta de violencia política, de que apenas hubo derramamiento de sangre (Baby, 2018) situación que resulta poco creíble. Debido a que, en el camino se vulneraron $\mathrm{DH}$ al establecerse toques de queda y al intervenir intermitentemente (Barrachina, 2016) a gente inocente como los indígenas aymaras.

Por lo expuesto, se tiene la argumentación de Gámez (2020), quien considera que, la violencia política ha estado en el parto de una nueva sociedad hasta donde se puede ver en todas las experiencias de transformación social, aunque la supuesta nueva sociedad no ha sido tan nueva sino solamente un nuevo modelo de la vieja, con otros dominadores en vez de los caducos y otros dominados en lugar de los que ya no podían vivir como antes pero pronto se acostumbraron a vivir una forma nueva de dominación. La violencia política ha estado ahí siempre, tan presente que a veces ni se le nota, ni se percibe cómo está ahí, acechando a unos mientras golpea a otros, cerrando los ojos a unos con múltiples distractores para que no vean que a otros les está cerrando los ojos para siempre o se los está arrancando.

\section{Metodología}

Dado el carácter explicativo, interpretativo y particular de los objetivos, este artículo contó con un enfoque cualitativo que se ha llevado a cabo a través de entrevistas en profundidad y grupo de discusión (E. Mora, Pujal i Llombart \& Albertín, 2017; Aparicio \& León, 2018; Suarez-Errekalde \& Royo, 2020; Huanca-Arohuanca et al., 2020) con un desarrollo de abordaje multifactorial, basada en un enfoque participativo sobre la base de las necesidades sentidas por la población (Aponte, 2017; Espejel \& Castillo, 2019; Rosales-Acosta, Pérez-Vidaurre, \& Dover-Carrillo, 2019; Carpio et al., 2019) superviviente de la NAM.

Teniendo en cuenta el estudio, la orientación del diseño se acentuó en la hermenéutica comprensiva, mediante un estudio del análisis de discurso y el análisis categorial de narrativas (Ospina-Ramírez et al., 2018) referidos al encuadre teórico-conceptual 
que definen las categorías de la tipificación y el ethos como conceptos base para el estudio interpretativo (Ordaz-Mejía \& Osorio-García, 2018). La técnica respectiva obedece a al análisis de discurso, los grupos de discusión que sucesivamente emplearon entrevistas semiestructuradas a doce actores (Muñoz-Cantero \& Losada-Puente, 2018) enmarcados dentro de la violencia política. Bajo esa premisa, la entrevista cualitativa pudo identificar la memoria de los sujetos, sus experiencias y visiones en un momento determinado (García, 2017; Huanca-Arohuanca, 2021).

\section{Grupos participantes}

Los actores materia de análisis, recae en las autoridades dirigenciales en la época del conflicto armado interno ocasionado por el SL y otros grupos insurrectos. Ahora bien, para establecer la muestra no probabilística de tipo intencionado y orientado teóricamente (Sandoval \& Carvallo, 2017) se consideró como eje de análisis y exégesis a las siguientes 2 organizaciones originarias manifiestas en la época de violencia política:

\section{Organización de 15 Comunidades Campesinas} $(15 C C)$. Organización encargada de garantizar justicia pluralista en la NAM.

2. Organización de 9 Comunidades Campesinas (9CC). Colectivo dedicado a velar por la seguridad e integridad de los aymaras.

Es preciso remarcar que se laboró con 12 actores claves, quienes en aquel contexto del conflicto armado interno en Perú eran dirigentes y representantes de las dos organizaciones $(15 \mathrm{CC}$ y 9CC) simétricamente divididos en seis para cada organización, con un promedio de edad que fluctúa entre cincuenta y ochenta años (tabla 1). Por tanto, las organizaciones campesinas de la NAM bajo los estándares y bordes que requiere la técnica de investigación, hicieron que se mantenga la originalidad y confiabilidad de sus alegatos en el tiempo en que duró los grupos de discusión (Huanca-Arohuanca, 2019b; Huanca-Arohuanca \& Geldrech, 2020).
Tabla 1.

Grupos de discusión en la investigación.

\begin{tabular}{lllll}
\hline Nombre & Edad & Sexo & Organización & Zona \\
\hline Carlos (S1) & 68 & $\mathrm{M}$ & $15 \mathrm{CC}$ & Alta \\
Víctor (S2) & 56 & $\mathrm{M}$ & $15 \mathrm{CC}$ & Alta \\
Cornelio (S3) & 76 & $\mathrm{M}$ & $15 \mathrm{CC}$ & Media \\
Eulogio (S4) & 80 & $\mathrm{M}$ & $15 \mathrm{CC}$ & Media \\
Hugo (S5) & 50 & $\mathrm{M}$ & $15 \mathrm{CC}$ & Baja \\
Jesús (S6) & 54 & $\mathrm{M}$ & $15 \mathrm{CC}$ & Baja \\
Néstor (S7) & 52 & $\mathrm{M}$ & $9 \mathrm{CC}$ & Alta \\
Rogelio (S8) & 64 & $\mathrm{M}$ & $9 \mathrm{CC}$ & Alta \\
Zacarias (S9) & 58 & $\mathrm{M}$ & $9 \mathrm{CC}$ & Media \\
Rubén (S10) & 50 & $\mathrm{M}$ & $9 \mathrm{CC}$ & Media \\
Lucio (S11) & 63 & $\mathrm{M}$ & $9 \mathrm{CC}$ & Baja \\
Edgar (S12) & 58 & $\mathrm{M}$ & $9 \mathrm{CC}$ & Baja \\
\hline
\end{tabular}

Fuente: elaboración propia.

\section{Procedimientos para la ejecución}

A partir del recuento de las organizaciones aymaras que visualizaron de cerca el conflicto evidente en Perú y la NAM, se ejecutó la selección de los actores directos e indirectos para su tratamiento metodológico. Siguiendo el método de Sandoval y Carvallo (2017) la recolección se llevó a cabo a través de pares simétricos para garantizar que los participantes cumplieran el requisito de ser autoridades o dirigentes de las ya mencionadas organizaciones. En tanto, los grupos de discusión proveyeron la apertura tomando en cuenta la realidad de los actores para de esa manera dialogar sobre las percepciones y reminiscencias a cerca de la violencia política perpetuada dentro de la NAM. Asimismo, las respuestas expresadas son de carácter voluntario, libre y consciente generados por los actores y no existe la manipulación por parte del que recolecta la información. En definitiva, los grupos de discusión se efectuaron entre enero y agosto de 2019, realizándose en primera instancia en sus respectivos distritos y teniendo la reunión final en la ciudad capital que duró un aproximado de 3 horas con previo consentimiento y rúbrica de los asistentes en honor a la veracidad (HuancaArohuanca, 2019b; Huanca-Arohuanca \& Pilco, 2021). 


\section{Resultados y discusión}

\section{Violencia política como síntoma de la crisis del Estado y el ascenso de SL en la NAM}

Para la NAM y todos los pueblos subalternos, la democracia ideal se sustenta en el vínculo igualitario entre gobernados y gobernantes. De ahí que, los primeros se encargan de garantizar irrestrictamente el buen gobierno, recordándoles que la paz es como una entonación poética, en el que los versos son simétricamente cantados por todos los civiles y los concurrentes al paíspueblo. El segundo cumple la función reguladora y supervisora de sus ciudadanos que apostaron y depositaron la confianza en aras de que sus libertades no sean trastocadas, por lo que garantizar la igualdad de oportunidades para los que menos tienen es la máxima de todo gobierno.

No obstante, en Perú de las 30 últimas décadas solo se ha encontrado gobiernos negligentes, populistas $\mathrm{y}$ dictatoriales que no han garantizado lo que por principio se buscaba en una nación y, por otro lado, se encontró a un pueblo débil, sumiso y analfabeto que desconocía casi en la totalidad sus derechos más elementales. No porque ellos quisieran estar en esa condición, sino porque, el Estado que les prometió una serie de derechos fundamentales y educación no lo hizo, más por el contrario, afianzó el odio, la discriminación $\mathrm{racial} / \mathrm{sexista} \mathrm{y} \mathrm{el} \mathrm{deseo}$ de la rebeldía.

Desde la independencia el Estado peruano nos odia, nos guarda rencor, nos discrimina y nos mata peor que animales... los aymaras merecemos respeto y reconocimiento... El Estado siempre nos ha marginado y silenciado de diferentes maneras. Creo que desde la época de los terroristas hasta la actualidad nada ha cambiado, siguen abusando de nuestros derechos... entonces como aymaras que somos tenemos que reaccionar ante esos abusos. Si nos unimos en contra del Estado abusivo estaremos en nuestra justa razón, o acaso tenemos que morir de rodillas, ¿no verdad?... (S10).

Como nos van a desaparecer de esa manera, se supone que nosotros hemos elegido al presidente para que nos proteja y no para que nos mate... Con el cuento del SL el chino ha asesinado a varios indígenas como yo, y los terrucos con el cuento de que éramos soplones mató a varios pobladores inocentes... lo único que queremos hoy, es justicia... ya no creemos en los gobernantes $k$ 'aras, nosotros queremos un presidente como el hermano Evo en Bolivia (S12).

En este apartado existe una clara evidencia de que, quienes gobiernan en Perú no han resuelto los problemas socioeconómicos y sobre todo los problemas políticos de carácter coaccionario. En esa medida, las organizaciones sociales de las $9 \mathrm{CC}$ y $15 \mathrm{CC}$ no sienten la representatividad de los denominados $k$ 'aras que han gobernado desde que inició la república, ya que, gobernantes como; Mariano Ignacio Prado, Alberto Fujimori y un Pedro Pablo Kuczynski de trascendencia extranjera han presidido el Perú. Los actores que representan a la NAM exigen un gobierno semejante al Estado Plurinacional de Bolivia. No porque sea un indígena $u$ originario, sino por la legitimidad que este ha tenido con su pueblo.

Por otra parte, los aymaras denuncian a los grupos insurgentes $y$ al Estado peruano de cometer genocidio en la NAM, ya que en el marco de la normatividad nacional los sucesos atroces han quedado de manera arbitral. Lo expresado, matiza un tanto con las matrices civilizatorias a la luz de las nociones de racismo real-doctrinario, genocidio y etnocidio (Arboleda, 2016) de los subversivos y del mismo gobierno de Colombia para con su población. Por lo que, en la legislación penal nacional peruana en materia de los delitos de genocidio, lesa humanidad y de guerra, hace falta instalar a través de un proceso de incorporación sistemática, las disposiciones de ciertos estatutos imperativos y la voluntad política de hacerlo fáctico (Villarreal, 2017; Casas \& Flores, 2018; Castro \& Téllez, 2018), para alcanzar los mínimos de justicia en los pueblos de la subalternidad.

\section{Revolución como fin último en el Altiplano Aymara de Perú}

En el Perú existen núcleos iniciales de revolución, desde el momento en que se toma conciencia de la invasión española hasta el momento del conflicto armado interno ocasionado por SL. En ese enfoque, la revolución puede ser considerado hasta cierto punto como un delito, una hostilidad y un levantamiento en contra del Estado o los poderes del Estado, de manera que, resulta inadmisible si éstas no tienen legitimidad ni son debidamente legales a los petitorios que en ella se plantean. Sin 
embargo, la NAM es conceptualizada como un pueblo cuna de la revolución en masa frente a las fuerzas externar que fomentan la explotación.

Los aymaras ancestralmente ya eran reaccionistas ante el poder y el maltrato de los mistis... Antes los grandes gamonales de los distritos de Ácora, Ilave, Laraqueri, Juliy Pomata tenían sus terrenos abusando a las comunidades campesinas, eran unos explotadores y ladrones. Por ejemplo, si un campesino no saludaba a los mistis, se le quitaban sus tierras, sus ganados y se llevaban todo... Ahora sigue lo mismo, los grandes vienen y desprecian a los aymaras, no valoran sus costumbres y los tratan como si fuera un perro... por todo eso, los aymaras reniegan, se sienten indignados y comenzaron a rebelarse ante un Estado que no hace nada por apoyarlos (S6).

Existe una exasperación hacia el Estado que se desentendió de los problemas que vivieron-viven sus habitantes en las diferentes periferias del Perú. Por ello, en la NAM los levantamientos contra el gobierno central están en proceso de latencia, en otras palabras, en cualquier momento pueden resurgir movimientos sociales en exigencia de ciertos derechos no constituidos y reconocidos por el Estado. Dado que, las organizaciones sociales estudiadas manifiestan el deseo de seguir en la lucha si sus condiciones sociales no cambian. Pero, lo que más llama la atención es que, en pleno siglo XXI siga existiendo la explotación y la negación del otro al estilo de la época feudal o el gamonalismo instaurado en el altiplano puneño en los siglos XVIII, XIX y XX. Si antes fueron los mistis quienes se ganaron el mérito de ser los explotadores por excelencia, al parecer hoy son los grandes los que tienen ese privilegio. En esa medida, cuando se habla de los grandes en la NAM se hace alusión a las empresas trasnacionales y multinacionales que concentran el poder económico en complicidad con el gobierno de turno para desconocer y desmerecer la opinión de los aymaras.

Nosotros hemos soportado muchas atrocidades de parte de los terroristas y el Estado... al parecer nunca nos han considerado como seres humanos... hay muchas familias que han perdido a sus seres queridos, ahora quien se responsabiliza por ellos, nadie... nuestra patria por culpa de los presidentes malos y asesinos está enfermo (S11).
La violencia generalizada ha logrado un nivel muy alto de deshumanización y al mismo tiempo una desontologízación real. El ser antropológico demacrado ya sea socialmente o económicamente suele recurrir como última instancia al colectivo para reorganizar su defensa. El Aymara cumple a la perpetuidad con lo anterior. Sin embargo, en la época del conflicto armado interno, a pesar de que no eran considerados como agentes de la clase más importante por los gobiernos de turno, éstos no tenían ninguna intención de recurrir a la violencia. Porque sabían que ese tipo sucesos solo traen pérdidas humanas manchado del dolor oscuro que asesina la conciencia de los hombres indígenas.

Cabe señalar que, cuando ya no se está conforme con los parámetros que maneja y establece el gobierno, la democracia puede ser cuestionada en todos los niveles y multiniveles de la esfera que lo constituye, de manera que, los actores representantes de las organizaciones sociales consideran que es correcto sublevarse contra los que tienen el poder, si este es opresor o vulnera los DH. Por su lado, SL hasta cierto punto planteó una contraofensiva para equiparar las condiciones de los más vulnerables con los que siempre han ostentado los abusos perpetuos. Sin embargo, todo cambió cuando aquellos grupos insurgentes comenzaron con los asesinatos selectivos y una serie de mecanismos de tortura hacia la población andina al cual le había prometido cambios sustanciales. Bajo esa premisa, la insurrección se puede reconfigurar como una revuelta supercompuesta por algunas comunidades o ciertos colectivos que en algún punto toman la decisión de contradecir al orden establecido arbitrariamente.

Siempre hemos respetado al Estado y las instituciones que lo acompañan... pero, no vamos a tolerar a un Estado que asesina y desaparece a nuestros hermanos al igual que los grupos terroristas... ¿qué mal hemos hecho los aymaras para ser masacrados y asesinados?... entonces, al ver una serie de atropellos en contra de nosotros, nace el odio contra "los grandes"... nunca olvidaremos las cosas que nos hicieron. Nuestras futuras generaciones recordarán que fuimos masacrados y en ellos estará presente nuestro sufrimiento (S7).

Se observa notoriamente que el ser ontológico Aymara, encuentra un grado de resentimiento en contra del Estado gobernado por los grandes y una repulsión por los grupos terroristas anuladores 
de línea que separaba el eros del tánatos como reconfiguración psicoanalítica freudiano. Paralelamente, se visualiza también el respeto genuino hacia el Estado y la vida humana como máximas de los sujetos antropológicamente constituidos. No obstante, queda la sangre ardiente y latente de los aymaras cuando manifiestan que el recuerdo no mata al olvido.

La idea de revolución parte desde el momento en que nosotros nacemos con la sangre Aymara... esa sangre que generación tras generación ha resistido a los invasores españoles y otros extranjeros... ya estamos cansados de tolerar las violaciones a nuestros derechos y que por cualquier cosa que les sucede a los gobernantes de turno, nosotros terminemos pagando todo... el pueblo Aymara está en su justa rebeldía y va ser totalmente legítimo la revolución que pueda darse en los próximos años para reivindicar nuestra libertad. Planteamos todo eso con la finalidad de alcanzar la justicia social (S5).

Si se pone énfasis en el discurso del S5, se podrá ver que existe la recomposición del otro en la narrativa subyacente de la reivindicación planteada por los aymaras con parentescos cualitativos y cuantitativos. De modo que, lo que al parecer ayuda de manera fundamental en la apertura del camino hacia la revolución es la sangre Aymara consuetudinaria proveniente del nosotros para dar la lucha por la igualdad y la justicia plural. Llegado a tal punto, existe la sospecha de que en cualquier circunstancia puede estallar una revolución generalizada en la NAM, porque, al parecer los originarios tienen razones de sobra para entrar a cerrar filas en contra de los que no han servido como nexos en el acceso a la justicia y la libertad.

Así mismo, desde la doctrina se fundamenta que la conducción del Estado peruano debe recaer en gobiernos con inclinaciones al diálogo y el respeto irrestricto de los DH en el marco de los Convenios Internacionales. Aquel gobernante que realiza su labor en función a lo ya mencionado, entonces, es-será democrático y no habrá discusiones incólumes que afecten la gestión política. Pero, si esta gestión actúa fuera del marco de la ley, violando la dignidad humana, se estaría ante un gobernante de facto o dictatorial ilegítimamente instaurado e implantado. En esa perspectiva, las percepciones de los dirigentes de las 9CC y $15 \mathrm{CC}$ hacen entrever, por un lado, que los tres gobiernos peruanos (Belaunde, García y Fujimori) no actuaron bajo los núcleos de legalidad $\mathrm{y}$, por otro lado, los insurgentes no comprendieron que el sometimiento de la población no ayudaría en la construcción del comunismo. En términos más sencillos, el socialismo que SL buscaba no cumplía con los talantes democráticos, ya que, era genocida por excelencia.

Necesitamos a un presidente que nos respete y que nos haga sentir seres humanos... ¿para qué queremos a un presidente que nos manda a matar? Cada vez que vamos a elegir, votamos con mucha esperanza de que tal vez este presidente pueda preocuparse por nosotros los pobres, tal como lo hizo Velazco (S3).

Existe una pérdida del antropocentrismo en los aymaras que a la larga data han soportado y visto desde muy cerca las atrocidades que el gobierno en compañía de los grupos sediciosos ha ido implantando en cada una de los grupos aborígenes. Los gobernados, quieren recobrar la humanidad perdida por los genocidios y las paranoias sistemáticas, apelando al diálogo-democrático que se habitualiza frecuentemente en el tiempo de las elecciones. En la NAM sus habitantes votan esperando ver en la prognosis una realidad mejor del que puedan hablar por generaciones, así como lo hacen de los buenos mandatarios que tuvo el Perú, como es el caso del general Juan Velazco Alvarado (1968 - 1975), gobernante que hizo factible la Reforma Agraria en todas las esferas de un Estado feudal constituido por siglos.

Lo declarado hasta aquí, pareciera que invita poner a flote los principios de trabajo clandestino para el correcto funcionamiento de las inteligencias revolucionarias categorizados en tres: la clandestinidad, la compartimentación y la verticalidad. Sabiendo que el primero, es descrita como un valor que tiene como base el secreto, no sólo como protección hacia fuera sino también a nivel interno de la organización. El segundo, se basa en fragmentar la información para garantizar que un golpe del enemigo haga un daño parcial y no total a la organización. Y el tercero, exige el respeto estricto de la jerarquización de arriba hacia abajo y viceversa de la organización y la aplicación de los principios leninistas del centralismo democrático (Acosta, 2020). Pero, ¿acaso los tiempos y las condiciones a la entrada del milenio actual no han cambiado? Al parecer para los habitantes de la NAM no, de ahí que, sigue intacto el deseo 
de la revolución para construir al hombre y la mujer, como de una propuesta osada y original se tratara (Casola, 2020; Huanca-Arohuanca, 2019a; Andrade, 2020).

\section{Represión-persecución y atentado a la libertad}

Desde la axiomatización de la violencia política por el Estado, grupos insurgentes y otros agentes anómalos, se puede desarrollar la represión y las persecuciones contra el principio elemental de la especie humanoide, denominado libertad. De manera que, los enemigos del Estado en decadencia, resultan ser los grupos sediciosos y el grupo de civiles inocentes que sedentarizan el pueblo subsumido en la pobreza y en el peor abandono desde que la República fue constituido. Por lo que se debe comprender de la represión, como el mecanismo de contención y moderación cuando el gobierno así lo tipifica en contextos de violencia política-social. También se puede decir que es, una manera de castigar a los culpables por medio del poder o la fuerza ejercida por la autoridad competente. Pero, si se analiza por los vectores del psicoanálisis se podrá asegurar que es un mecanismo de defensa creado por el subconsciente del Estado para garantizar la paz. Cualquiera de los acercamientos a la definición en concreto, no justifica que dentro de la represión existan las violaciones de los DH y la destrucción del sujeto, solo para desestabilizar a un grupo que no está conforme con el gobierno o que una población vulnerable tenga que vivir en medio del genocidio.

Los culpables son otros... ¿por qué nos buscan, por qué nos hacen daño?... no es suficiente con matar a nuestros hermanos inocentes... nuestras familias viven muy asustados hasta ahora, cuando escuchan por los medios de comunicación a cerca del terrorismo o el Estado, tiemblan... tienen miedo no porque sean culpables, sino, porque han matado a inocentes y cuando escuchan esas palabras creen que los matarán también (S6).

El más implacable genocidio nunca jamás contado en la historia de los peruanos, es el asesinato de miles de personas inocentes que tuvieron la mala suerte de nacer en tiempos caóticos y que se convirtieron en daños colaterales del Estado y los grupos terroristas como: SL y MRTA. Pues, el miedo a la represión violenta que se conspiró contra los aymaras se vuelve cada día más intenso sumado por el seno del odio, la paranoia y una serie de patologías que afectan nocivamente al subconsciente de los que habitan el altiplano puneño.

Es más, los parámetros establecidos desde el Leviatán de Hobbes hasta la actual Constitución Política del año 1993 implantado cuasidemocráticamente por el gobierno de Fujimori en las agencias subnacionales del país, denotan claramente el rechazo absoluto a las acciones represivas y maltratos que el gobierno efectuó hacia los ciudadanos, atentando los DH dentro y fuera de su jurisdicción. En ese sentido, la persecución se delimita como el conjunto de acciones con agravantes y acosos de algunos colectivos específicos sobre otros colectivos, además, se puede comprender como la contención ejercida de un gobierno hacia sus propios gobernados con el cual tienen diferencias políticas, culturales y religiosas. $\mathrm{Si}$ es así como se comprende la persecución, entonces, cabe la posibilidad de argumentar que, en la NAM las acciones criminales de los grupos terroristas y los mecanismos represivos del Estado son graves.

El Estado siempre nos ha seguido para incriminarnos sobre ciertos delitos que no hemos cometido... pero, no solo los militares nos buscaban sino también los terrucos para que apoyemos a la lucha armada... pues, sino hacíamos lo uno o lo otro nos matarían... una vez vinieron los militares y nos dijeron: si nos dicen quienes son los terrucos en este cochino pueblo, les vamos a sacar la mierda y les vamos a matar como a los perros que son... (S2).

Queda claro, cuando por naturaleza los gobiernos autoritaristas incitan al odio y la crueldad sobre la sociedad civil, no importa si aquellos ciudadanos son culpables o inocentes. Al parecer el fin se contempla en la implantación de una paranoia generalizada en todas las dimensiones posibles, tal como sucedió en todo el territorio pan-peruano. Los medios que utilizan los gobiernos de facto a través de sus (AAE) para tapar sus propios delitos es acusar e incriminar a gente inocente que no tiene los mecanismos de defensa legal, ya que, carecen de todo y muestran una condición de vulnerabilidad. Por otro lado, el terrorismo solo cambia los medios bélicos para atentar contra la dignidad humana de los aymaras, porque el fin sigue siendo lo mismo. El genocidio de casi 500 
años, se denominaba conquista y evangelización a los indígenas, en la época del conflicto armado interno tenía otro rostro, su rostro se llamaba terrorismo de Estado y SL sintetizado en una serie de desapariciones forzadas a nivel nacional y local.

El terrorismo de SL en las esferas altiplánicas se incrementó de 15, en 1983, a 22 en 1984 y a 33 en 1985. En 1986 los senderistas efectuaron 83 ataques y el número de víctimas ascendió a 32 . En 1987, las acciones de violencia se redujeron después que la columna senderista fuera diezmada en Cututuni, registrándose 35 ataques; éstos, sin embargo, se incrementaron a 77 en 1988 y a 97 en 1989 (CVR, 2003b). De manera que, las divergencias, no se habían podido concretar por dos factores principales: de un lado, la oposición dentro de SL, y del otro, la decisión del régimen de Fujimori, quien "prosiguiendo la línea y política genocida del Estado peruano aplicó creciente represión militar dejando de lado una solución política para el término de la guerra" (Rénique, 2003, p. 125).

De todo el apartado, resulta de gran relevancia analizar la pérdida de la soberanía del Estado peruano frente a SL y la misma población Aymara que fue perdiendo su libertad a causa de los dos anteriores, en tanto que Estado es el garante históricamente reconocido de los DH (Jara, 2020). Por tanto, para Ferrajoli (1999) son derechos fundamentales todos aquellos derechos subjetivos que corresponden universalmente a todos los seres humanos en cuanto dotados del estatus de personas, de ciudadanos o personas con capacidad de obrar; entendiendo por derecho subjetivo cualquier expectativa positiva (de prestación) o negativa (de no sufrir lesiones) adscrita a un sujeto por una norma jurídica, y por estatus la condición de un sujeto, prevista asimismo por una norma jurídica positiva, como presupuesto de su idoneidad para ser titular de situaciones jurídicas o autor de los actos que son ejercicio de éstas (Cardona et al., 2018) para garantizar legítimamente la libertad.

\section{Paranoia en los andes y el deseo de un gobierno pluralista}

Después de casi treinta años de oprobio sembrado por SL y los miembros de las fuerazs armadas bajo las órdenes del gobierno de FujimoriMontesinos, quedan como rastros nocivos los efectos colaterales que la NAM ha soportado. De manera que, el resultado anómalo es, la paranoia generalizada en todos los habitantes en el que el terrorismo se perpetuó. En contextos definitorios, la paranoia se explica como un trastorno mental en el que las personas poseen un profundo miedo y desconfianza de sus semejantes. En ese sentido, se puede sostener que los aymaras hasta la actualidad experimentan persecuciones de parte de Estado y de SL. Esa sensación de persecución resulta ser tan grande para los que habían presenciado el terrorismo, que no desean ni mencionar la palabra sendero o terruco, por temor a ser encarcelados extra judicialmente y fuera del marco internacional de los DH. Dicho lo a priori, hablan los actores.

Nos dijeron que si mencionabas la palabra "sendero o terruco" nos llevarían a la cana (cárcel)... el Chino quiere ver a todos en la cana, sean culpables o inocentes, todos entran dijeron... por eso nosotros ya no queremos saber nada comunistas o socialistas, si hablamos de eso nos pasará lo mismo que al hermano Francisco... solo porque un terruco se le acercó y le habló lo desaparecieron... el ejército por largo tiempo estuvo buscando de casa en casa para ver si teníamos los libros de Marx. Mao. Lenin. Abimael Guzman, El Che y otros afiches... solo querían sembrarnos para desaparecernos... como podrían acusarnos y mentirnos de esa manera, si nosotros ni siquiera sabemos leer (S4).

Se observa claramente la intención del Estado peruano de acabar con SL a costa de los daños colaterales que aquello implicaría el asesinato de miles de ciudadanos originarios en Perú y una parte de la NAM. Está claro que, al igual que los grupos sediciosos el gobierno de Fujimori-Montesinos se caracterizó por la utilización masiva/selectiva/ ilegal/clandestina de las formas de violencia con el propósito de anular a los indígenas supuestamente vinculados a SL e imponer un estado de terror en todas las esferas y formas del mundo de la vida Aymara. Así mismo, se observa el principio de culpar al otro sin los medios probatorios necesarios, a pesar de que exista un leve contacto a los grupos en juicio. La idea del gobierno y los grupos insurgentes es clara, ya que, el propósito de ambos grupos es sembrar odio, terror, sensaciones de persecución, delirios y paranoias en los habitantes de los andes, con la única finalidad de subyugarlos y hacerles creer que su lucha es legítima. 
De cualquier modo, las dictaduras autoritaristas y fundamentalistas que se caracterizaban por tener a un monótono líder como lo fue el de Fujimori y Abimael Guzmán, han debilitado casi por completo a los gobiernos pluralistas con inclinaciones alternas al neoliberalismo. Contradiciendo lo anterior, es que en la NAM se apuesta por gobiernos pluralistas que respeten la dignidad, la igualdad, la solidaridad y la justicia.

Honestamente queremos gobiernos como el de Bolivia. Este modelo que maneja el Perú solo favorece a los ricos... luchamos para que gobiernos como la dictadura del chino Fujimori no vuelvan nunca más... somos gente al que les gusta hablar con la verdad, no toleramos la falsedad (S9).

Resulta eminente la construcción de un modelo pluralista similar al Estado Plurinacional de Bolivia, que por trece años fue conducido por el indígena Evo Morales con el cliché del Socialismo del siglo XXI. Pero, por otro lado, existe un rechazo abismal a los gobiernos dictatoriales como de Alberto Fujimori, quien manejó una política neoliberal de exclusión y rechazo hacia los pobres. En definitiva, el deseo de una revolución que todavía no llega seguirá siendo para los habitantes de la NAM una ilusión latente que dodo gobierno deberá tomar en consideración, sabiendo que, la ontología de los aymaras no contiene las preposiciones de falsedad, porque, esos términos atentan la veracidad y la realidad genuina del
Lo analizado hasta esta parte del manuscrito, pone de manifiesto que el miedo a perder la vida, a ser secuestrado, o a ser víctima de un robo, ha generado un estado de paranoia común, visible en las entrevistas realizadas (Castillo \& Reguant, 2017) en la NAM. A ello se añade el hecho de que la paranoia de la vigilancia y la seguridad interna han contribuido, bajo pretexto de la lucha contra el terrorismo, al debilitamiento contrahegemónico de los movimientos sociales y dificultando sus movimientos transfronterizos (De Sousa, 2018; Lárez, 2019; Huanca-Arohuanca, 2020) como de los aymaras supervivientes de la violencia política.

\section{Conclusiones}

Los contenidos de la violencia política en el Perú y la Nación Aymara obedecen al quebrantamiento de los Derechos Humanos y una serie de violaciones sistemáticas a la dignidad humana, tanto por los agentes del Estado y los grupos insurgentes que ejecutaron una serie de zozobras y represiones inquisitorias, como si del medioevo se tratara, solo para obligar a las víctimas, sean culpables o no, a la elección de vivir con la muerte. De manera que, como se explicó en el desarrollo del estudio, el gobierno buscó culpar a los supuestos sospechosos de sedición sin los medios probatorios que exige la norma jurídica en el Perú y los organismos internacionales. Por su parte, los segmentos de Sendero Luminoso aniquilaron lo único que les quedaba a los indígenas aymaras, su vida. Por consiguiente, hoy, los aymaras viven con el deseo de la autonomía y la revolución para quebrar por así decirlo, la sentencia de vivir en el olvido $\mathrm{y}$ en el peor abandono de sus representantes y la eliminación total de cualquier ideología dogmática sumergido en el tánatos que atenta a la dignidad y a la vida misma.

Cabe mencionar que, la violencia política tiene su propia historia en el corazón de los peruanos que sufrieron los daños de manera directa $o$ indirecta. Dado que, el conflicto armado interno en referencia a la Nación Aymara tiene connotaciones psicológicas fulminantes que ha deteriorado el subconsciente de los actores, creando delirios de persecución (paranoia) en las víctimas y el deseo de revolución contestataria contra los grupos insurgentes y el mismo Estado que en su momento fue cómplice del genocidio hacia el núcleo de los habitantes de la Nación Aymara. En definitiva, solo la apertura de los canales democráticos vinculantes entre el gobierno y los aymaras podrá redefinir nuevos espacios de diálogos transdisciplinares custodiados por la verdad y la justicia imperativa.

\section{Referencias bibliográficas}

Acosta, C. (2020). Férrea pero consciente: disciplina y lazo identitario en las organizaciones clandestinas de las Fuerzas Armadas Revolucionarias de Colombia-Ejército del Pueblo (FARC-EP). Izquierdas, 49, 541-553. https://search. proquest.com/openview/286a1e9bd6e 8021 ccef91c1d9b3f9673/1.pdf?pq-origsite $=$ gscholar\&cbl=4393311

Andrade, V. M. (2020). La Teoría Crítica $\mathrm{y}$ el pensamiento decolonial: hacia un proyecto emancipatorio post-occidental. 
Revista Mexicana de Ciencias Políticas y Sociales, 65(238), 131-154. Doi: 10.22201/ fcpys.2448492xe.2020.238.67363

Aparicio, J. M., \& León, M. M. (2018). La música como modelo de inclusión social en espacios educativos con alumnado gitano e inmigrante. Revista Complutense de Educación, 29(4), 1091-1108. Doi: 10.5209/RCED.54878

Aponte, M. (2017). Regionalismos estratégicos, empresas nacionales y transnacionales de hidrocarburos en Estados Unidos y América Latina. Revista Problemas Del Desarrollo, 191(48), 27-54. http://probdes.iiec.unam.mx

Arboleda, S. (2016). Plan Colombia: descivilización, genocidio, etnocidio $\mathrm{y}$ destierro afrocolombiano. Nómadas, 45, 7590. http://www.scielo.org.co/pdf/noma/n45/ n45a06.pdf

Baby, S. (2018). Le mythe de la transition pacifique. Violence et politique en Espagne (1975-1982). Ediciones Akal.

Barrachina, C. (2016). Democracia, política y violencia en Honduras (2006-2014). Península, 11(1), 25-64. Doi: 10.1016/j. pnsla.2016.01.002

Barreto, I., \& Borja, H. (2007). Violencia política: algunas consideraciones desde la psicología social. Revista Diversitas - Perspectivas En Psicología, 3(1), 109-119. https://www. redalyc.org/pdf/679/67930107.pdf

Canessa, M. F. (2011). La violencia política en el mundo laboral peruano. Debates En Sociología, 36, 85-106. http://revistas.pucp. edu.pe/index.php/debatesensociologia/ article/view/2167/2098

Cardona, L. Á., Ortiz, H., \& Vázquez, D. (2018). Violación de derechos humanos en México. Un costo poco advertido de la corrupción. Política y Gobierno, 25(1), 153-184. http:// www.scielo.org.mx/pdf/pyg/v25n 1/16652037-pyg-25-01-153.pdf

Carpio, A., Hancco, M. S., Cutipa, A. M., \& Flores, E. (2019). Estrategias del marketing viral y el posicionamiento de marca en los restaurantes turísticos de la Región de Puno. Comuni@ccion: Revista de Investigación En Comunicación y Desarrollo, 10(1), 70-80. Doi: 10.33595/2226-1478.10.1.331

Casas, A., \& Flores, L. (2018). Entre memoria y olvido: el 2 de octubre de 1968. Revista Mexicana de Ciencias Políticas y Sociales, 234, 201-214. Doi: 10.22201/ fcpys.2448492xe.2018.234.65717

Casola, N. (2020). Cuando se quebró el muro.
Algunas notas acerca de la crisis en el Partido Comunista argentino durante los años 1980. Izquierdas, 49, 1752-1771. http:// www.izquierdas.cl/images/pdf/2020/n49/ art89 1752 1771.pdf

Castillo, T., \& Reguant, M. (2017). Percepciones sobre la migración venezolana: causas, España como destino, expectativas de retorno. Migraciones, 41, 133-163.

Castro, A. C., \& Téllez, R. F. (2018). Exploring the origin of our ancestors: the birth of the Nasa people: the history of a genocide. Revista Republicana, 24, 181-201. Doi: 10.21017/ Rev.Repub.2018.v24.a46

Comisión de la Verdad y Reconciliación. (2003a). Anexo 2. ¿Cuántos peruanos murieron? Estimación del total de víctimas causadas por el conflicto armado interno entre 1980 y el 2000. In Informe Final, 9 tomos. CVR.

Comisión de la Verdad y Reconciliación. (2003b). Capítulo 3. Secuelas económicas. In Informe Final, 9 tomos. CVR.

Cotler, J. (1997). El Sendero Luminoso de la destrucción. Nueva Sociedad, 150, 90-97. https://nuso.org/media/articles/ downloads/2613 1.pdf

Cueva, G. (2005). Intervenciones en salud mental en víctimas de violencia política. Revista de Psiquiatría y Salud Mental Hermilio Valdizán, 6(1), 23-32. http://www.hhv.gob. pe/wp-content/uploads/Revista/2005/I/3INTERVENCION EN SALUD MENTAL EN.pdf

De Sousa, B. (2018). Constitución y hegemonía. Luchas contra la dominación global. Chasqui. Revista Latinoamericana de Comunicación, 136, 13-31.

Degregori, C. I. (2011). Qué difícil es ser Dios. El Partido Comunista del Perú - Sendero Luminoso y el conflicto armado interno en el Perú: 1980 - 1999. Instituto de Estudios Peruanos, IEP.

Espejel, A., \& Castillo, I. (2019). Environmental education in the baccalaureate: From school to family. Alteridad, 14(2), 231-242. Doi: 10.17163/alt.v14n2.2019.07

Ferrajoli, L. (1999). Derechos y garantías: La ley del más débil. Trotta.

Fukuyama, F. (1989). The End of History? The National Interest, 16, 3-18. https://www. embl.de/aboutus/science society/discussion/ discussion 2006/ref1-22june06.pdf

Gámez, M. E. (2020). La violencia en la historia. El papel de la memoria frente al trauma y la 
guerra. Utopía y Praxis Latinoamericana. Revista Internacional de Filosofía Iberoamericana y Teoría Social, 25(90), 6376. Doi: $10.5281 /$ zenodo.3872481

García, P. (2017). Etnografía y Ciencia Política: la excepcionalidad del caso español. Política y Sociedad, 54(1), 249-269. Doi: 10.5209/ POSO. 48938

Huanca-Arohuanca, J. W. (2019a). El despertar de una nueva era: colonización y camino hacia la revolución. Revista Revoluciones, 1(1), 1-3. http://revistarevoluciones.com/index.php/rr/ article/view/1/2

Huanca-Arohuanca, J. W. (2019b). El discurso filosófico y la violencia política en la Nación Aymara - Acora [Universidad Nacional del Altiplano]. http://repositorio.unap. edu.pe/bitstream/handle/UNAP/12758/ Huanca Arohuanca Jesús Wiliam. pdf? sequence $=1 \&$ is Allowed $=\mathrm{y}$

Huanca-Arohuanca,J.W.(2020). Contrahegemonía y la lucha por la educación en el sur del Perú. Editorial Académica Española.

Huanca-Arohuanca, J. W. (2021). Narrativas de guerra y resistencia: participación de la mujer austral del Perú en la Guerra del Pacífico. Encuentros. Revista de Ciencias Humanas, Teoría Social y Pensamiento Crítico, 13, 5362.

Huanca-Arohuanca, J. W., \& Geldrech, P. (2020). Planificación educativa y gestión pedagógicaestratégica-operacional en las instituciones del nivel inicial en el sur del Perú. Revista Conrado, 16(76), 369-376. https://conrado. ucf.edu.cu/index.php/conrado/article/ view/1497

Huanca-Arohuanca, J. W., \& Pilco, N. (2021). Acciones revolucionarias en ámérica Latina: Puno y el Alto Perú durante el proceso de independencia (1809-1825). Chakiñan. Revista de Ciencias Sociales y Humanidades, 14. Doi: 10.1590/SciELOPreprints. 1364

Huanca-Arohuanca, J. W., Canaza-Choque, F. A., Escobar-Mamani, F., \& Ruelas, D. (2020). En defensa del pluralismo latinoamericano: las esferas de la justicia y la igualdad compleja en Michael Walzer. Un dilema pendiente por atender. Revista Chakiñan, 11, 92-103. Doi: 10.37135/chk.002.11.07

Huntington, S. (1993). The Clash of Civilizations? Foreign Affairs, 72(3), 22-49. http:// www.guillaumenicaise.com/wp-content/ uploads/2013/10/huntington clash-ofcivlizations.pdf
Jara,A.M.(2020).Globalización, transnacionalidad $\mathrm{y}$ desprotección de los derechos humanos. Revista Mexicana de Ciencias Políticas y Sociales, 65(238), 19-47. Doi: 10.22201/ fcpys. 2448492xe.2020.238.65576

Lárez, R. (2019). Pensar la contrahegemonía: Incertidumbres filosóficas y políticas de Álvaro B. Márquez-Fernández. Utopía y Praxis Latinoamericana. Revista Internacional de Filosofía Iberoamericana y Teoría Social, 24(1), 2-3. Doi: 10.5281/zenodo.3110438

Lúnecken, G. A. (2000). Violencia Política (Violencia política en Chile. 1983-1986). LOM Ediciones.

Mora, E., Pujal i Llombart, M., \& Albertín, P. (2017). The gender vulnerability contexts of chronic pain. Revista Internacional de Sociología, 75(2), 1-12. Doi: 10.3989/ ris.2017.75.2.15.60

Muñoz-Cantero, J.-M., \& Losada-Puente, L. (2018). Implicaciones de la actitud docente en la calidad de vida del alumnado con alteraciones del desarrollo intelectual. Educación XX1, 21(2), 37-58. Doi: 10.5944/ educXX1.19535

Ordaz-Mejía, D., \& Osorio-García, M. (2018). Significados del viaje turístico en jóvenes millenials. Caso de estudio: Texcoco. Revista Latinoamericana de Ciencias Sociales, Niñez y Juventud, 16(2), 897-912. Doi: 10.11600/1692715x.16217

Ospina-Ramírez, D., López-González, S., BurgosLaitón, S., \& Madera-Ruiz, J. (2018). La paz entre lo urbano y lo rural: imaginarios de paz de niños y niñas sobre el posconflicto en Colombia. Revista Latinoamericana de Ciencias Sociales, Niñez y Juventud, 16(2), 943-960. Doi: 10.11600/1692715x.16220

Rénique, J. L. (2003). La voluntad encarcelada. Las "luminosas trincheras de combate" de Sendero Luminoso del Perú. IEP Ediciones.

Rosales-Acosta, A., Pérez-Vidaurre, R., \& DoverCarrillo, Y. (2019). Building a Methodology for the Learning of English in Rural Context: Learners Insights. Revista Electrónica Educare, 23(1), 1-24. Doi: 10.15359/ree.231.14

Sandoval, J., \& Carvallo, V. (2017). Discourses on politics and democracy by Chilean students from different youth organizations. Revista Española de Ciencia Política, 43, 137-160. Doi: 10.21308/recp.43.06

Suarez-Errekalde, M., \& Royo, R. (2020). El rol de las representaciones corporales mediáticas 
en la esfera sexual de personas de ideología feminista. Papers, 105(1), 143-171. Doi: 10.5565/rev/papers. 2586

Talancón, J. H. (2018). Violencia Política. In Ensayos sobre Violencia Política. No a la violencia política y violencia política por razón de género. Procuraduría General de la República. http://www.fepade.gob.mx/swb/ fepade/Contacto

Valdés, F. (2020). Derechos humanos, democracia y Estado en la tercera ola de la autocracia. Revista Mexicana de Ciencias Políticas y Sociales, 65(239), 61-84. Doi: 10.22201/ fcpys.2448492xe.2020.239.72341

Vera-Márquez, A. V., Palacio, J., Maya, I., \& Holgado, D. (2015). Identidad social y procesos de adaptación de niños víctimas de violencia política en Colombia. Revista Latinoamericana de Psicología, 47, 167---
176. Doi: 10.1016/j.rlp.2015.06.006

Villarreal, A. (2017). Los crímenes de genocidio, lesa humanidad y de guerra. Notas para su incorporación a la legislación mexicana. Anuario Mexicano de Derecho Internacional, 17, 187-218. Doi: 10.22201/ iij.24487872e.2017.17.11035

Wieviorka, M. (1992). Terrorismo y violencia política. Revista Internacional de Sociología, 2, 169-178. https://www. insumisos.com/lecturasinsumisas / TERRORISMOYVIOLENCIAPOLITICA MichelWieviorka.pdf 